\title{
Invited Commentary: Reshaping Surgery as an Emerging Global Health Priority
}

\author{
Sarah Lombardo ${ }^{1} \cdot$ Raymond R. Price $^{1}$
}

Published online: 24 June 2016

(C) Springer International Publishing AG 2016

Keywords Global health · Access to surgery · Surgical care · Lancet Commission on Global Surgery

On June 29, 1980, Halfdan Mahler, then DirectorGeneral of the World Health Organization (WHO), identified surgical care as a practical and essential element of public health. Calling the lack of access to surgical care the "most serious manifestation of social inequity in health care," he presented to members of the global health community three challenges: to recognize the issue, to compile a list of essential surgeries, and to work to ensure the availability of these lifesaving procedures for all people [1]. More than three decades would pass before Dr. Mahler's call to action would be answered.

A timely response from both surgeons and nonsurgeons was hindered by several factors, some owing to a lack of knowledge and others to misperception. During this period, surgical care for developing nations was believed to be too expensive, too technically challenging for low- and middle-income countries (LMICs), and a luxury reserved for the economically privileged. Funds allocated for global health were prioritized to provide essential medicines and public health interventions to combat select communicable diseases, such that long-term investments in health in-

Raymond R. Price

rayrprice@comcast.net

1 University of Utah, Center for Global Surgery, Salt Lake City, UT, USA frastructure were not made. Today, as a result of this myopia, more than two-thirds of the world's population-nearly 5 billion people-lack timely access to basic life-saving surgical care [2]. Current estimates place the unmet surgical need at 143 million procedures per year in LMICs [3]. Additionally, in excess of 100 million people worldwide sustain traumatic injuries each year, resulting in 5.8 million deaths; more than malaria, HIV, and tuberculosis combined (Fig. 1). Yet, the US global research and development funding for trauma is 32 times less than the budget for malaria, HIV, and tuberculosis [4]. Indicative of the lack of knowledge with regards to the burden of surgical disease in prior decades, there are no similar estimates from the 1980s available for comparison.

Only since the turn of the century has high quality epidemiologic data specific to surgical disease begun to elucidate its staggering burden and the overwhelming economic impact on societies in LMICs. The anticipated economic loss attributable to untreated surgical disease in LMICs from 2015 to 2030 is USD \$12 trillion [2] (Fig. 2). The recommendation of the Lancet Comm ission on Global Surgery to allocate USD $\$ 420$ billion to scale-up surgical services for 88 LMICs must be viewed as an investment, not a cost. The 2012 Copenhagen Consensus, a year-long project involving more than 65 researchers including 4 Nobel Prize laureates for economics, recognized strengthening surgical capacity as one of the smartest ways to allocate money to respond to ten of the world's biggest challenges [5]. These findings lend support to the growing call for greater international commitment to improving surgical capacity worldwide as one of the most cost-effective interventions in medicine, both in high- and lowincome settings [6]. 


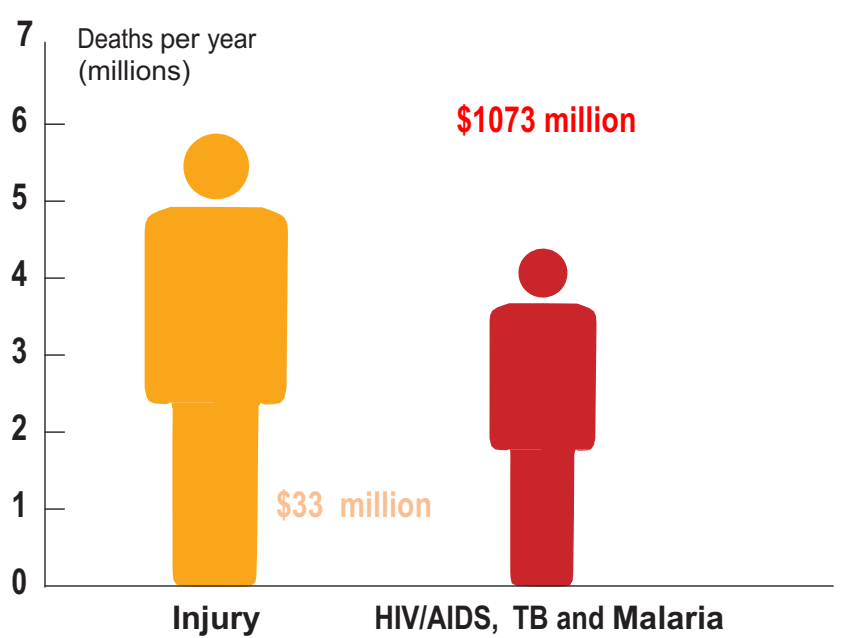

Fig. 1 Deaths from injury compared to HIV/AIDS, TB, and Malaria. Note US Global Research and Development funding in millions of dollars. Figure modified and reproduced with permission from World Health Organization. http://www.who.int/violence_injury_ prevention/key_facts/VIP_key_facts.pdf

The global surgical community has responded to this compelling data with an urgency and effort commensurate to the surgical need. Following a 7-year grass-roots worldwide advocacy campaign, on May 22, 2015, the World Health Assembly (WHA), the policy-making body of the World Health Organization (WHO), adopted resolution WHA 68.15, "Strengthening emergency and essential surgical care and anaesthesia as a component of universal health coverage" [7]. This groundbreaking document, unanimously approved by all 194 Member States of the United Nations, is the first formal international consensus to acknowledge surgery and anesthesia as key public health priorities. The resolution calls upon Member States to integrate surgical and anesthetic care into their National Health plans and to develop local health infrastructure capable of "providing a core set of emergency and essential surgery and anaesthesia" at the primary care and first referral hospital levels. Other key messages include a need for increased collaboration within the surgical community, the development of international surgical standards, and continued work to improve data collection and context-appropriate research. This resolution serves as a framework to improve surgical and anesthetic care in LMICs for governments, professional societies, academic institutions, and non-governmental organizations.

Surgeons across the world have taken on these new challenges with a purpose-driven efficiency characteristic of their profession. Just prior to the historic WHO resolution, the Lancet Commission on Global Surgery published its own report highlighting the substantial social, economic, and health impact of surgical care, and offering goal-oriented strategies to overcome common roadblocks and pitfalls in care delivery [2]. The Lancet Commission was formed in 2014 and is an internationally represented body of experts in surgery, anesthesia, obstetrics, oncology, health care policy, financing, economics, and research, with affiliates in more than 110 countries. The result of this highly collaborative effort is a comprehensive and adaptable action plan for LMIC governments and stakeholders, with special attention to the financial burden and ongoing research needs of surgical care in these environments. A number of the core
Fig. 2 Annual and cumulative GDP loss in low-income and middle-income countries from five categories of surgical conditions. Based on the WHO Projecting the Economic Cost of Ill-Health (EPIC) model. (2010 US\$, purchasing power parity. $G D P$ gross domestic products. Reproduced with permission from Lancet Commission on Global Surgery: http://media.wix. com/ugd/346076 23b4c3a24 c594888a8f0e077195dc5d8.pdf

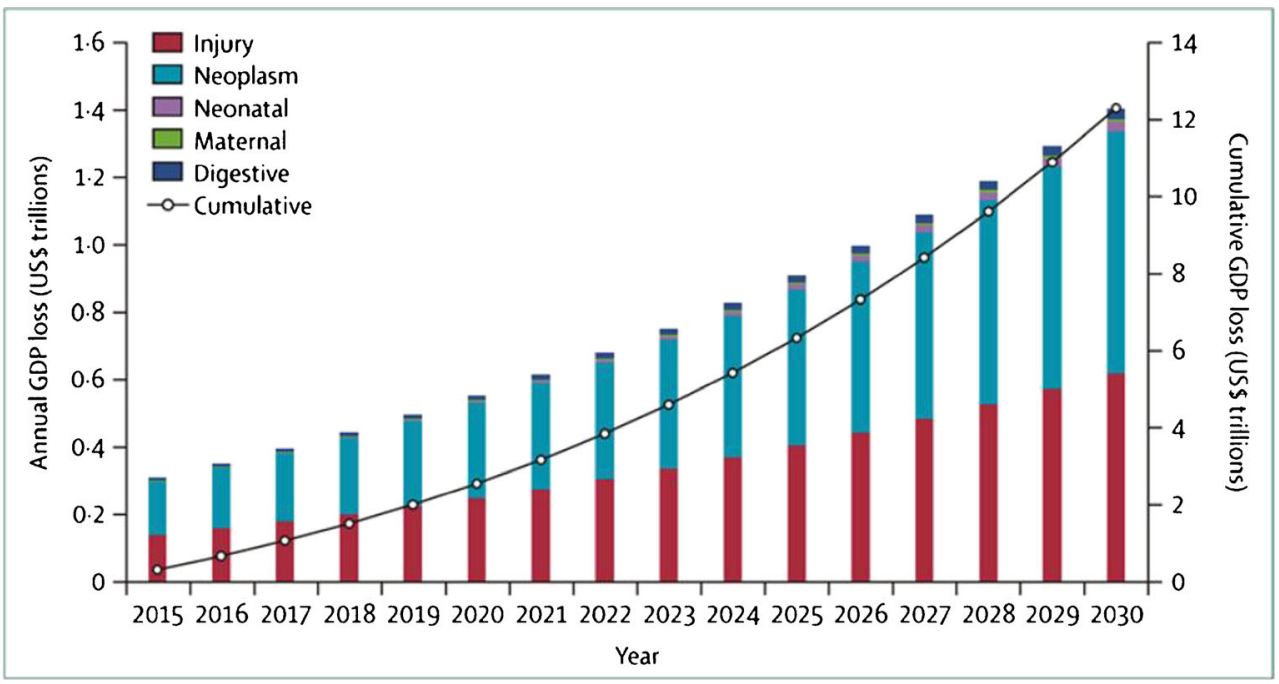


indicators proposed by the Lancet Commission have been integrated into the World Bank's 100 core sector indicators providing globally accepted standard metrics to measure the progress for expanding surgical care. The Lancet Commission on Global Surgery has already begun assisting efforts to implement National Surgical Plans in Cape Verde, India, and Zambia.

Surgeons and anesthesiologists must assume a leadership role guiding other societies and organizations to ensure continuation of the health gains made in LMICs over the past two decades. The Global Alliance for Surgical, Obstetrical, Trauma, and Anesthesia Care (G4 Alliance) is dedicated to building political priority for safe surgical care through advocacy, policy design, and fundraising [8]. Since 1990 maternal mortality has been cut nearly in half through implementation of projects emphasizing maternal education and training of birth attendants. However, an estimated 289,000 women still died in 2013 as a result of peripartum complications, many of which required surgical care that was unavailable [9] (Fig. 3). By highlighting the ubiquitous role of surgery in the management of disease traditionally targeted by global public health efforts, such as maternal mortality, the G4 Alliance hopes to develop a broad base of political and social support towards a goal of achieving $80 \%$ global surgical access by 2030. The International Relations Committee and Operation Giving Back (OGB) of the American College of Surgeons, as well as the Academic Association of Surgeons, are similarly dedicated to stimulating research, education, and advocacy among the surgical community though funded awards and fellowship positions.

The global burden of surgical disease is substantial, and much work remains to be done to fully understand and address the unique social, economic, and political impact of the unmet surgical need. But the role of surgical care, with its ability to save lives, mitigate lifelong disabilities, and improve economic output for individuals, families, and communities, is finally gaining recognition as a global public health priority and as an essential and transformative part of the healthcare delivery system. From large multinational organizations such as the Lancet Commission on Global Surgery, the World Bank, and the G4 Alliance, to the growing number of professional societies and academic institutions, surgeons across the world are working hard to ensure that safe surgical care will one day be an "indivisible, indispensable part of health care" for all people [1].

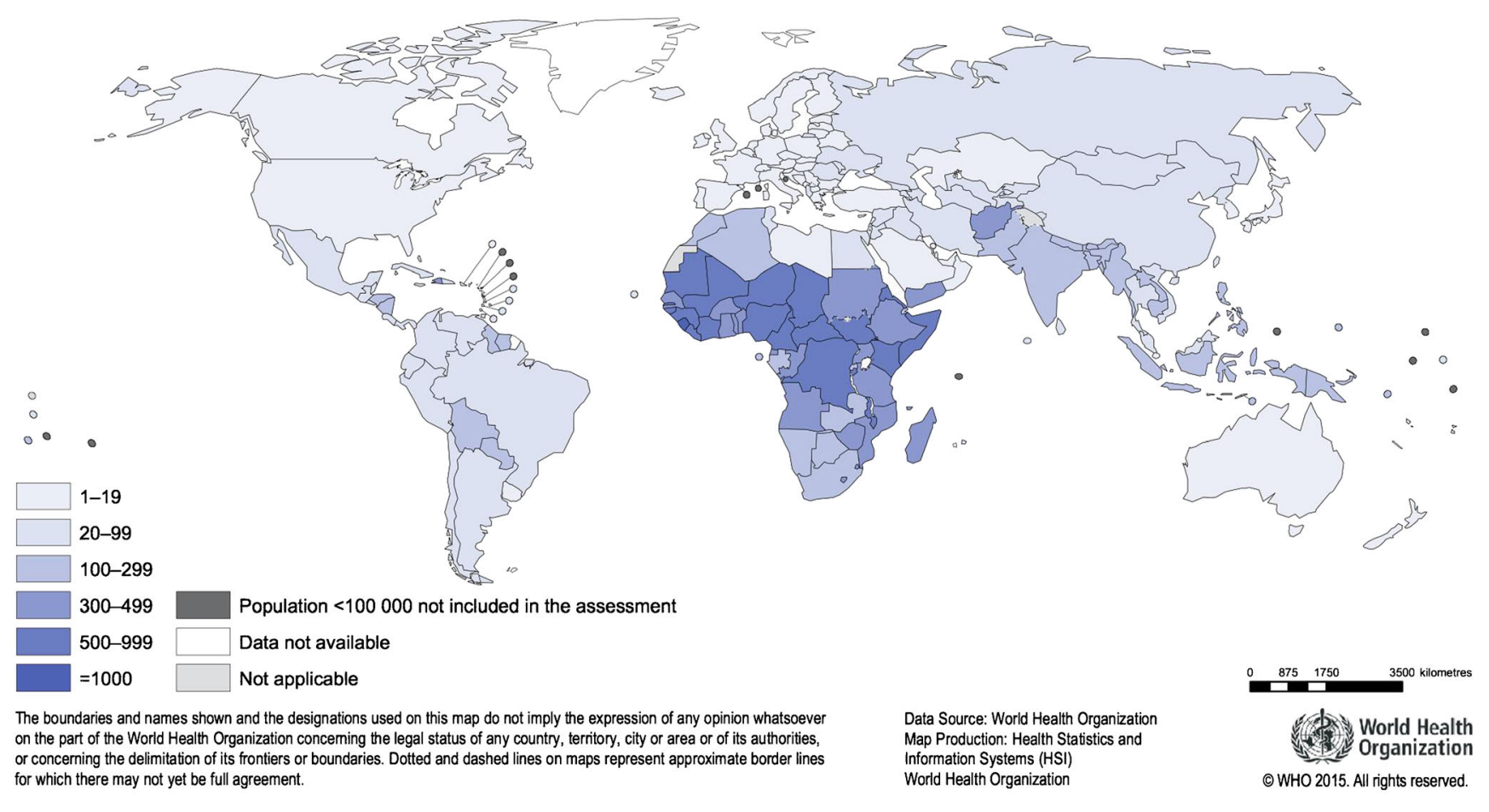

Fig. 3 Map illustrating worldwide maternal mortality. An estimated 289,000 women died in 2013 as a result of peripartum complications, many of which required surgical care that was unavailable. Reproduced with permission from the World Health Organization. http://apps.who. int/iris/bitstream/10665/193994/1/WHO_RHR_15.23_eng.pdf?ua=1 


\section{References}

1. Mahler H. Surgery and Health for All. Mexico City: World Congress of the International College of Surgeons; 1980.

2. Meara JG, Leather AJM, Hagander L, et al. Global Surgery 2030: evidence and solutions for achieving health, welfare, and economic development. Lancet. 2015;386:569-624.

3. Mock CN, Donkor P, Gawande A, et al. Essential surgery: key messages from Disease Control Priorities, 3rd edition. Lancet. 2015;385: 2209-19.

4. Wexler A, Kates J. The U.S. global health budget: analysis of appropriations for fiscal year 2015. The Henry J. Kaiser Family Foundation, December 22, 2014. http://kff.org/global-healthpolicy/issue-brief/the-u-s-global-health-budget-analysis-ofappropriations-for-fiscal-year-2015/. Accessed 27 May 2016.

5. Jamison, D, Jha, P, Laxminarayan, R, and Ord, T. Copenhagen consensus 2012 challenge paper. Infectious disease, injury and reproductive health. http://www.oxfordmartin.ox.ac.uk/downloads/academic/201205 Infectious+Disease.pdf. Accessed 25 May 2016.

6. Chao TE, Sharma K, Mandigo M, et al. Cost-effectiveness of surgery and its policy implications for global health: a systematic review and analysis. Lancet Glob Health. 2014;2:e334-45.

7. Price R, Makasa E, Hollands M. World Health Assembly Resolution WHA68.15: "Strengthening Emergency and Essential Surgical Care and Anesthesia as a Component of Universal Health Coverage" Addressing the Public Health Gaps Arising From Lack of Safe, Affordable, and Accessible Surgical and Anesthetic Services. World J Surg. 2015;39(9):2115-25.

8. Alliance $\mathrm{G}$. The global alliance for surgical, obstetrical, trauma, and anaesthesia care, 2016. http://www.theg4alliance.org/. Accessed 25 May 2016.

9. Maternal Mortality Fact Sheet (2013). World Health Organization. November 2015. http://www.who.int/mediacentre/factsheets/fs348 /en/index.html. Accessed 25 May 2016. 